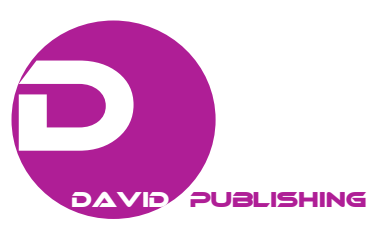

\title{
Total Quality Management Implementation Failure Reasons in Healthcare Sector
}

\author{
Nicolas Nicolaou and George Kentas \\ University of Nicosia, Cyprus
}

\begin{abstract}
Although TQM's advantages and benefits have been identified by the literature, the ways to achieve them continue to remain complex. Nevertheless, in many cases TQM failure is not due to vague and ambiguous procedures, but for certain reasons. We conduct an in-depth literature review from peer reviewed journals regarding Total Quality Management (TQM) implementation failure reasons only for healthcare sector. A comparative analysis for TQM implementation failure reasons was conducted in order to identify the most common. The most common TQM implementation failure reasons in healthcare sector are lack of management commitment, change of culture, quality tools and techniques not applied correctly, not adequate time for implementation, lack of resources and information, data validity, cost of investment, management's resistance to empower employees and professional's resistance. Most of studies in TQM concern successful implementation in hospitals, clinics and health organizations. Our literature review showed that very few studies in the literature focus on failure reasons of TQM implementation. This study can help healthcare managers to study each failure reason separately and proceed to appropriate actions in order to avoid possible TQM implementation failure. The novelty of this paper is that failure reasons of TQM implementation concern only healthcare sector.
\end{abstract}

Key words: TQM failure reasons, TQM obstacles, healthcare.

\section{Introduction}

Even Total Quality Management is in early stage of researching and development [1-3], it is often mentioned as a "social movement" [4]. TQM is considered as an attempt to improve organization's competitiveness and effectiveness [5], as well as a "comprehensive way to improve total organizational performance and quality" [6]. Due to increased patients' demands for improved quality services as well as health practise, healthcare organizations face continual provocation and challenges. Therefore, an improvement of the procedures and the way healthcare departments are organized and managed is required [7]. Hence, healthcare managers have turned to TQM in order to achieve quality improvement of service and reduce cost [8].

Although TQM's advantages and benefits have been identified by the literature [8-13], the ways to achieve them continue to remain complex and hazy

Corresponding author: Nicolas Nicolaou, Ph.D., research fields: health care management.
[14]. TQM approach has not a clear and directed path. But it has principles and goals. It's on management's decision to choose the appropriate way to achieve them. It has a difficult and abnormal approach, with many failure reasons. Not all approaches lead to successful implementation [15]. According to Dale et al., TQM has been characterized as a "fallen star". Adoption of TQM has more difficulties in healthcare sector than industry [16]. Nevertheless, in many cases TQM failure is not due to vague and ambiguous concept [17], but for certain reasons and obstacles. Most of the studies in the literature concern concept of TQM [18].

The aim of this paper is to identify the most common failure reasons of TQM implementation in healthcare sector, in order to prepare healthcare managers to avoid possible failure consequence of TQM implementation.

\section{Materials and Methods}

We conduct an in-depth literature review from peer reviewed journals regarding Total Quality Management 
(TQM) benefits and advantages. Subsequently, we focus our in-depth literature review to failure reasons for TQM implementation only for healthcare sector.

A comparative analysis for TQM implementation failure reasons was conducted in order to identify the most common.

\section{Results and Analysis}

Failure reasons vary for TQM implementation among industries. Healthcare industry faces the most of them [19]. Each implementation procedure faces different obstacles, problems or wrong approach to TQM. Since human factor has a major role in TQM implementation procedures, most common failure reasons have to be identified in order to be avoided for successful implementation. Some of the most common failure reasons of TQM implementation into healthcare organizations are:

Lack of management commitment. According to the literature, this is the most common failure reason of TQM implementation. Management ought to be commitment to the target. Ought to provide support and inspiration to employees in order to achieve TQM implementation. TQM approach must be clearly by a specific framework and management have to communicate and often to explain framework's stages in order to achieve desired results. Where framework's stages are vague, supportive intervention by management is imperative. Management have to mention benefits and advantages of TQM implementation very often in every opportunity or situation can do it [13, 20-27].

Change of culture. This is the most difficult and time consuming stage of TQM implementation. This is due to employees' fear and thus resistance to changes. Employees with current culture are more difficult to proceed to changes into their daily procedures than employees with quality oriented culture. Therefore, in this stage management have to achieve change of current culture to quality oriented culture in order to have "smooth" TQM implementation [13, 19, 25-30].

Quality tools and techniques not applied correctly. This reason concerns wrong usage of quality tools and techniques for each problem or obstacle intended to be managed. Wrong usage of quality tools and techniques will lead to invalid data collection. Hence, improvements will not be achievable if not valid information is available. Management ought to have basic knowledge regarding quality tools and techniques in order to use them appropriately. Otherwise, employees will have to be trained to use quality tools and techniques [26, 31].

Not adequate time for implementation. TQM approach is a long term and timely journey. Basic principles of TQM need time to be adopted and adjusted by employees. Adequate time has to be given in order to achieve TQM implementation [32]. According to Chakravarty et al (2001) "TQM is not panacea or an Aladdin's lamp. It has to be understood, incorporated and nurtured and then only the fruit tasted". Thus, TQM is not appropriate method for quick solutions. Adequate time is compelling for successful implementation [8].

Lack of resources and information. The availability of resources and information is very important issue for TQM implementation because those data will be managed accordingly in order to be used for the successful implementation. A preparation has to be strived by management in order to define availability of adequate resources and information for TQM approach. Available resources such as employees who would be interested to use TQM tools and techniques. And information such as available quality tools and techniques as well as any other data that would be important to be used into tools and techniques $[13,18$, 33].

Data validity. TQM is a data based decision approach. Facts and data used for TQM implementation must be accurate, reliable and always on time. The results from quality tools and techniques have to be valid as well as consistent. Therefore, TQM 
tools and techniques have to be used efficiently by trained in data analysis employee [13].

Cost of investment. Due to limited resources and budget, healthcare organizations have to choose the most appropriate way to use them in order to have return. Most of the times, healthcare organizations prefer to invest on a direct return investment instead of long term return investment. May a TQM implementation advantage be cost reduction, but most of healthcare managers prefer instant return of investment. Most of the times information technology or even medical equipment is the preferred investment option instead of TQM approach [8].

Management's resistance to empower employees. Due to daily work pressure and high patients' demand, management resists taking away employees from direct care work for training or participating to quality teams. In this case, management prefers to accomplish short term instead of long term goals. Taking employees away from direct care work may create new obstacles into daily procedures. Consequently management has to understand that those obstacles are temporarily regarding TQM's long term benefits [8].

Professionals' resistance. TQM approach tends to promote corporation among healthcare professionals. Tends to improve relations and mutual support among professionals into work environment. However, healthcare professionals often resist to corporate with other healthcare professionals within hospital. Also, resist towards learning new and updated medical methods [8].

Uncertain returns from TQM implementation. TQM implementation procedure does not have safe advantages and benefits. If TQM does not implement in an appropriate to current circumstances way, it does not promise certain results. Management has serious doubts concerning return from implementing TQM. Due to literature, evidence from successful implementation of TQM is mixed. Therefore, a hesitation for implementation of TQM by management is noted [8].

\section{Conclusions}

TQM failure reasons are a considerable issue and have to be studied in depth. It has to be discussed and analysed among healthcare managers in order to know what to expect but mostly know what to avoid. A well-prepared manager can perform his/her management skills in a better and more efficient way if he/she knows the most common failure reasons. This study can help healthcare managers to study each failure reason separately and proceed to appropriate actions in order to avoid possible TQM failure.

According to the literature, Total Quality Management (TQM) has an increased number of successful implementation in Europe through the last decade. Most of studies in TQM concern successful implementation in hospitals, clinics and health organizations [8]. Our literature review showed that very few studies in the literature focus on failure reasons of TQM implementation. This study though, provides the most common TQM failure reasons for healthcare organizations. The novelty of this paper is that failure reasons of TQM implementation concern only healthcare sector.

\section{References}

[1] Bunney, H., and Dale, B. 1997. "The implementation of quality management tools and techniques: A study." The TQM Magazine 9 (3): 183-9.

[2] Chakravarty, A., Parmar, N., and Ranyal, W. 2001. "TQM-The New Paradigm in Health Care Management." Medical Journal Armed Forces India 226-9: 57.

[3] Dahlgaard, J., Kristensen, K., and Kanji, G. 1998. Fundamentals of Total Quality Management. London: Chapman \& Hall.

[4] Dale, B. G. et al. 2001. "Total quality management and theory: An exploratory study of contribution." Total Quality Management \& Business Excellence 12 (4): 439-49.

[5] Dale, B., and Shaw, P. 1999. Managing Quality. 3rd ed. Oxford: Blackwell Publishers.

[6] Dale, B., Zairi, M., Van der Wiele, A., and Williams, A. 2000. "Quality is dead in Europe-long live excellence- - true or false?" Measuring Business Excellence 4 (3): 4-11. 
[7] Dayton, N. 2003. "The demise of total quality management." The TQM Magazine 15 (6): 391-6.

[8] Dean, J., and Bowen, D. 1994. "Management theory and total quality: Improving research and practice through theory development." Academy of Management Review 19 (3): 392-418.

[9] Early, J., and Godfrey, A. 1995. "But it takes too long....." Quality Progress 28 (7): 51-5.

[10] Evans, J., and Lindsay, W. 2002. Tha Management and Control of Quality. 5th ed. Ohio, USA: Thomson Learning.

[11] Hackman, J., and Wageman, R. 1995. "Total quality management: empirical, conceptual, and practical issues." Administrative Science Quarterly 40 (June): 309-42.

[12] Hunt, V. 1993. Managing Quality: Integrating Quality and Business Strategy. Homewood, IL: Irwin.

[13] Jafari, S. M., and Setak, M. 2010. Total Quality Management Tools and Techniques: The Quest for an Implementation Roadmap. Malaysia, Proceedings of the AGBA 7th World Congress.

[14] Mehralian, G., Nazari, J. A., Reza Rasekh, H. R. R., and Hosseini, S. 2016. "TOPSIS approach to prioritize critical success factors of TQM: Evidence from the pharmaceutical industry." The TQM Journal 28 (2): 235-49.

[15] Mohammad Al-Ali, A. 2014. Developing a Total Quality Management Framework for Healthcare Organizations. Bali, Indonesia, Proceedings of the 2014 International Conference on Industrial Engineering and Operations Management.

[16] N.A.S, N. A. o. S. I. o. M. 1998. The future of public health. Washington, DC: National Academy Press.

[17] Oakland, J. 1993. Total Quality Management: The Route to Improving Performance. London: Butterworth Heinemann.

[18] Ovretveit, J. 2000. "Total Quality Management in European Healthcare.” International Journal of Health Care Quality Assurance 13 (2): 74-9.

[19] Powell, T. 1995. "Total quality management as competitive advantage: A review and empirical study." Strategic Management Journal 16: 15-37.

[20] Prajogo, D., and Sohal, A. 2003. "The Relationship between TQM Practices, Quality Performance, and Innovation Performance." International Journal of Quality \& Reliability Management 20 (8): 901-18.
[21] Radovilsky, Z., Gotcher, J., and Slattsveen, S. 1996. "Implementing Total Quality Management, Statistical analysis of survey results." International Journal of Quality and Reliability Management 13 (1): 10-23.

[22] Ramseook-munhurrun, P., Munhurrun, V., and Panchoo, A. 2011. "Total Quality management adoption in a public hospital: evidence from Mauritius." Gobal Journal of Business Research 5 (3): 67-77.

[23] Rensik-West, T. 1994. "Avoiding barriers to quality implementation." The Total Quality Review 4 (1): 19-22.

[24] Shea, J., and Gobeli, D., 1995. "TQM: the experiences of ten small businesses." Business Horizons January/ February: 71-7.

[25] Siddiqui, F., Haleem, A., and Wadhwa, L. 2009. "Role of Supply Chain Management in Context of Total Quality Management in Flexible Systems: A State-of the-Art Literature Review." Global Journal of Flexible Systems Management 10 (3): 1-10.

[26] Sitkin, S., Sutcliffe, K., and Schroeder, R. 1994. "Distinguishing control from learning in total quality management: a contingency perspective." Academy of Management Review 19 (3): 537-64.

[27] Srdoc, A., Sluga, A., and Bratko, I. 2005. "A quality management model based on the deep quality concept." International Journal of Quality \& Reliability Management 22 (3): 278-302.

[28] Talib, F., Rahman, Z., and Azam, M. 2010. Total Quality Management Implementation in the Healthcare Industry: A proposed Framework. Jalandhar, India, Department of Industrial and Production Engineering.

[29] Tatikonda, L., and Tatikonda, R. 1996. "Top ten reasons your TQM effort is failing to improve profit." Production and Inventory Management Journal 37: 5-9.

[30] Vouzas, F., and Psychogios, A. 2007. "Assessing managers' awareness of TQM." The TQM Magazine 19 (1): $62-75$.

[31] Westcott, R. 2005. The Certified Manager of Quality/ Organizational Excellence Handbook. 3rd ed. Milwaukee, Wisconsin: ASQ Quality Press.

[32] Yang, C., 2003. "The establishement of a TQM system for the healthcare industry." The TQM Magazine 15 (2): 93-8.

[33] Yousuf, N., 2011. "Total Quality Management: Do health profession educators need to be educated?" Education in Medicine Journal 3 (2): e65-9. 